VARANDA, Jorge. Cuidados biomédicos de saúde em Angola e na Companhia de Diamantes de Angola, c. 1910-1970. História, Ciências, Saúde - Manguinhos, Rio de Janeiro, v.21, n.2, abr.-jun. 2014, p.587-608.

\title{
Cuidados biomédicos de saúde em Angola e na Companhia de Diamantes de Angola, c. 1910-1970
}

Biomedical health care in Angola and in the Companhia de Diamantes de Angola, circa 1910-1970

\section{Jorge Varanda}

Professor, Faculdade de Ciências e Tecnologia/Universidade de Coimbra; investigador, Centro em Rede de Investigação em Antropologia/Instituto Universitário de Lisboa, e Centro de Malária e Outras Doenças Tropicais/ Universidade Nova de Lisboa. Faculdade de Ciências e Tecnologia. Rua Sílvio Lima, Universidade de Coimbra - Polo II 3030-790 - Coimbra - Portugal

jorge.varanda@gmail.com

Recebido para publicação em novembro de 2012.

Aprovado para publicação em julho de 2013.

http://dx.doi.org/10.1590/S0104-59702014000200008

\section{Resumo}

Pretende-se caracterizar a prestação de cuidados biomédicos em Angola durante a atividade da Companhia de Diamantes de Angola. Uma análise comparativa de políticas e práticas de saúde pública de vários atores coloniais, como os serviços de saúde da Companhia, sua congénere do Estado e outras empresas coloniais, revelará diferenças de investimento na saúde, isto é, instalações e pessoal de saúde, e tratamentos. Este escrutínio bem como as condições de vida iluminarão o carácter idiossincrático e central dos serviços de saúde da Companhia em termos de morbimortalidade em Angola, e a centralidade destes para as representações de um império cuidador.

Palavras-chave: saúde pública; morbimortalidade; colonialismo; Companhia de Diamantes de Angola; Angola.

\section{Abstract}

The scope of this paper is to analyze the provision of biomedical care in Angola during the activities of the Companhia de Diamantes de Angola. A comparative analysis of public health policies and practices of various colonial actors, such as the health services of the Company, its state counterpart and other colonial companies, will reveal differences in investment in health, namely in health facilities, personnel and treatment. This survey as well as the living conditions highlight the idiosyncratic and central nature of the health services of the Company in terms of morbidity and mortality in Angola, and the importance of these representations for a caregiving empire.

Keywords: public health; morbimortality; colonialism; Companhia de Diamantes de Angola; Angola. 
$\mathrm{D}$ urante parte do século XX, com particular acuidade nas últimas décadas do Terceiro Império Português, ${ }^{1}$ o governo português reiterava continuamente que seu projeto colonial era particularmente atento em termos de cuidados biomédicos para com as populações locais. Para cumprir tal objetivo o governo recorreu amiúde a representações coloniais relativamente aos serviços de saúde da Companhia de Diamantes de Angola (Diamang) e mais tarde a "validações" por instituições internacionais da qualidade destes serviços. Apesar de tal ocorrer num contexto "desalinhado" com a realidade vivenciada no terreno, esta foi uma das representações coloniais mais fortes, na tentativa vã do Estado português de demonstrar a efetividade da missão civilizadora e consequente manutenção do projeto colonial. Os Serviços de Saúde da Diamang (SSD) são o foco principal, demonstrando-se como eram um serviço de saúde sem par na colónia e centrais para as representações de um império cuidador.

Este artigo pretende caracterizar, lato sensu, a prestação de cuidados biomédicos em Angola entre as décadas de 1910 e 1970. Através de uma análise comparativa de políticas e práticas de saúde pública de vários atores coloniais, nomeadamente, SSD, Serviços de Saúde e Higiene de Angola (SSHA), ou seja, estatais, e outras empresas coloniais como os Caminhosde-Ferro de Benguela (CFB) e Sociedade Agrícola do Cassequel (Cassequel), ilustrar-se-ão as diferenças de investimento em sistemas de saúde biomédicos, isto é, instalações, pessoal de saúde e tratamentos. Ao avaliar as políticas e práticas de saúde, bem como as condições de vida em várias regiões, iluminar-se-á o carácter idiossincrático e central dos SSD em Angola em termos de morbimortalidade ${ }^{2}$ entre o período em análise, por volta das décadas de 1910 a 1970, e em paralelo a situação problemática experienciada por populações locais até a década de 1960.

Embora seguindo o caminho aberto por Shapiro (1983), pretende-se ir além de mostrar o hiato entre discursos oficiais e realidade em Angola. Este texto procura mostrar as diversas políticas de saúde pública vigentes em Angola em diferentes períodos, contribuir para melhor caracterização do dia a dia vivenciado pelas diversas populações, e, apesar de não ser o objeto do artigo, levantar o véu sobre seu relacionamento com a biomedicina. Consequentemente questionar-se-ão representações do império como entidade una e "coerente" entre diversas áreas, urbanas ou rurais, bem como a ideia de uma "medicina colonial" em que a aplicação dessas políticas era efetuada em uníssono entre serviços públicos e privados presentes no vasto território, indo, assim, em contracorrente com a maioria dos textos analíticos sobre essa temática. ${ }^{3}$ Em resumo, este texto pretende ser um estudo exploratório sobre a ação de vários serviços de saúde de atores coloniais.

A escolha de uma visão mais abrangente, em termos geográficos e temporais, retira força a detalhes. Partindo de investigação de arquivos, relatórios coloniais e publicações contemporâneas e bibliografia mais recente sobre as entidades industriais que operaram em Angola nesse período, recorre-se a triangulações metodológicas e leituras against e along the grain (contra/a favor de pelo) para ilustrar a prestação dos serviços de saúde (Prakash, 1994; Stoler, 2009). O objetivo é colmatar uma lacuna na historiografia e caracterizar mais sistematicamente as questões da saúde e doença na Angola sob ocupação colonial.

Os constrangimentos inerentes a um artigo impedem que se aprofundem diversas questões, como, por exemplo, a aplicação dos programas de saúde pública e as diversas agendas ativas no contexto; questões relacionadas com a capacidade de agência às ações/respostas dos 
locais, da caracterização de africanos dóceis ou colonizados, ou da construção do discurso biomédico sobre os africanos, entre outras. ${ }^{4} \mathrm{O}$ intuito do artigo é apenas caracterizar as ações dos sistemas de saúde pública mais importantes no projeto colonial (Estado, Cassequel e CFB), comparando-os com os SSD.

\section{$O$ dealbar do século $X X$}

A Conferência de Berlim representou o início de uma nova era nos projetos coloniais. ${ }^{5}$ Com essa Conferência, a argumentação, amiúde empregue por Portugal, relativamente aos direitos históricos tornava-se secundária. A manutenção de colónias passou a estar relacionada com a ocupação efetiva e gestão adequada dos territórios e populações autóctones. Nesse novo "paradigma" ganharam relevância aspectos ligados à saúde (Lyons, 1991). Esses novos pressupostos não tinham em consideração que a biomedicina, aqui considerada medicina produzida no Ocidente, teria que esperar quase meio século até ter instrumentos capazes, leia-se medicamentos eficazes (Patterson, 1981), para poder combater a pletora de doenças que contribuíam para que grandes áreas africanas fossem ainda consideradas o cemitério de brancos (Curtin, 1990). Apesar disso a biomedicina era argumento central, justificação para a ação civilizadora, isto é, projeto colonial, e permitia a exploração dos territórios em face da manutenção de exércitos e pessoal branco com saúde. Somente numa fase posterior, final da segunda década do século XX, deu-se maior atenção à mão de obra local. Apesar da dificuldade da ciência médica ocidental em lidar com enfermidades locais, a biomedicina tinha entrado no rol de justificações das ações das potências imperiais - Reino Unido, França, Bélgica, Portugal (Arnold, 1988). No caso português a saúde esteve no centro do discurso colonial até ao fim do império, logo importa melhor compreender como foram (na realidade) os investimentos em saúde pública por parte dos diversos atores coloniais ao longo das quase seis décadas sob análise.

\section{A Companhia de Diamantes de Angola}

A Diamang explorou jazigos diamantíferos de aluvião c. de 1917 a 1974 no canto nordeste de Angola, distrito da Lunda, circunscrição do Chitato. ${ }^{6} \mathrm{O}$ contrato assinado com o governo em 1921 atribuía-lhe várias vantagens pouco usuais: direitos de exploração diamantífera, isenção quase total de pagamento de impostos, administração da área contratual e respectivas populações e, no caso da saúde, independência de ação em face do Estado (Diamang, 1921).

O papel ímpar dessa companhia relaciona-se com o facto de ter sido o principal contribuinte para os cofres coloniais; fiador anual da colónia em face de empréstimos internacionais; maior empregador da colónia, superando 27 mil trabalhadores diretos no final do período colonial; de ter expandido sua área de administração sanitária dos contratuais $20.000 \mathrm{~km}^{2}$ para mais de $50.000 \mathrm{~km}^{2}$; e, como se mostrará neste artigo, de apresentar um serviço de saúde sem par na colónia, central para as representações de um império cuidador para com as populações autóctones.

A Diamang era, portanto, a companhia majestática, a mais importante companhia da joia do império, a colónia de Angola. Apesar da centralidade dessa companhia no Terceiro Império Português, a bibliografia académica existente é escassa. As obras de Newitt (1981), 
Clarence-Smith (1985), Pélissier (1986-1988), Telo (1994), Freudenthal (2001), Birmingham (2006) apresentam uma imagem muito lata da Diamang. Só recentemente essa lacuna está lentamente a ser colmatada. Areia (1985), Porto (2009), Varanda (2007) e Cleveland (2008) escreveram mais em detalhe sobre a companhia, respectivamente sobre cestos adivinhos usados pelas populações Tshokwe; Museu do Dundo e consequente produção e uso de ciência; os seus serviços de saúde e sua relação com a produção diamantífera ao mais baixo custo; ou questões relacionadas com a mão de obra da companhia. Essas investigações contribuíram para caracterizar seu modus operandi particular de colonialismo científico e a influência particular sobre as representações coloniais.

\section{Um esquisso de serviços de saúde}

Até ao século XX, as obras de Walter (1953) e Pina (1943) sobre os problemas da organização médico-sanitária, bem como a tese de licenciatura de Abranches Pinto (1967) e Cadornega (1972), fornecem algum "alimento" para o pensamento sobre a presença da biomedicina em Angola desde o século XVIII. Mais recentemente, as publicações de Dias (1995) em drogas medicinais empregues em Angola entre séculos XVI e XVIII, de Walker (2004a, 2004b, 2005) sobre medicina popular portuguesa e o seu uso nas colónias, juntamente com as de Kananoja (2010, 2012) sobre crioulização em processos de cura em Angola no século XVIII permitem uma visão mais complexa sobre a relação entre medicina ocidental e tradicional empregue por colonizadores e locais.

A norma até ao final do século XIX foi de serviços de saúde coloniais, isto é, estatais, constituídos por um quadro exíguo de profissionais de saúde cujo trabalho, por norma, era cuidar da saúde do governador ou outro pessoal administrativo de alta patente. ${ }^{7}$ Esse padrão de "sistema de saúde" teria algumas melhorias no século XX, resultado das três reorganizações do sistema estatal, em que se inscrevia a imposição legal de companhias privadas com determinada dimensão também prestarem cuidados biomédicos (Varanda, 2007). Assim, até ao início do século XX permaneceram intactos o viés racial e a centralização geográfica dos cuidados de saúde na capital ou cidades costeiras importantes em que estavam colocados a população-alvo e os funcionários administrativos ou militares. Os trabalhadores e populações locais presentes no "resto" do território eram relegadas para o esquecimento ou para a prestação de cuidados básicos por várias missões religiosas.

\section{Saúde e condições de vida na expansão do Estado colonial c. das décadas de 1900 a 1930}

Embora a Conferência de Berlim seja um marco fundamental na aplicação dos projetos imperiais, ela não produziu efeitos imediatos referentes à ocupação efetiva do território ou prestação de cuidados biomédicos em Angola. Até à década de 1920 continuaram a realizarse inúmeras expedições militares com o intuito de subjugar militarmente populações locais "insurretas" e a posteriori ocupar o território militar, administrativa e por último sanitariamente. No entanto, só na década de 1930, com o estabelecimento da administração colonial por toda a colónia, é que o jugo colonial foi sentido com acuidade pelas populações. As "guerras 
de pacificação" (expressão colonial) ativas até aos anos 1940 em diversas áreas da colónia testemunhavam a dificuldade que o Estado tinha para ocupar e administrar o território (Pélissier, 1986-1988). Os corolários dessas ações militares para as populações locais eram reiteradamente a privação alimentar, doenças e altas taxas de mortalidade.

A autora Jill Dias (1981, p.349) refere outros fatores que também concorreram para esse cenário de fome, epidemias e despovoamento, mas que simultaneamente facilitavam a ocupação do território pela potência imperial. A autora nota que o fim do equilíbrio ecológico e epidemiológico entre os recursos alimentares, população e doenças teve início ainda no primeiro quartel do século XIX com a exploração comercial, coadjuvado com situações climatéricas extremas - seca, chuva, pestes de gafanhotos - persistindo até 1940 . As situações de fome eram acompanhadas por incidência elevada de doenças como malária, doença do sono e epidemias de varíola, contribuindo para elevada mortalidade (p.370). A população da área entre os rios Dande e Kwanza, por exemplo, caiu para metade entre 1876 e 1898, e em 1930 ainda não se tinha recuperado. A depressão financeira internacional dos anos 1930 e as políticas centralizadas de Salazar na economia metropolitana concorriam para esse cenário dantesco. Desse modo, foi sem "grande surpresa" que durante grande parte do século XX os SSHA tentavam essencialmente matizar essa situação. Isso mesmo sentiu a Diamang ao iniciar a exploração de diamantes na Lunda.

Ao "chegar" à circunscrição do Chitato em 1917 a Diamang deparou-se com um território "vazio", um espaço em que a "civilização" colonial ainda não se tinha feito sentir. Os postos administrativos eram pontos isolados numa paisagem com pouquíssimos exemplos da presença colonial. Para explorar industrialmente os diamantes de aluvião, a companhia viu-se forçada a criar as condições para tal, o que implicou edificar nas quase seis décadas seguintes, além das explorações industriais mineiras, estradas, pontes, vilas e cidades, barragens, redes elétricas e estruturas de saneamento básico. Esse panorama ilustrava bem o esquecimento a que tinham sido relegadas as zonas do interior, pelo governo da colónia e nas quais o sistema de saúde estatal não era exceção.

A legislação relacionada com a temática da saúde publicada pelo alto-comissário Norton de Matos (1921-1924) é indicativa do desenvolvimento frugal verificado desde sua primeira passagem como governador-geral da colónia uma década antes (Cleveland, 2000). A carência de orçamento e de pessoal que os serviços de saúde estatais sentiam na década de 1920 indiciava um cenário que permaneceria até aos anos 1950 (Fonseca, 1953).

No primeiro Congresso de Medicina Tropical de África Ocidental, em 1923, em Luanda, as apresentações sobre os serviços de saúde de Angola recorriam a uma retórica elaborada para minorar uma realidade verificável pela colónia. Num raro alerta o chefe dos SSHA, doutor Damas Mora, notava que cada uma das cem circunscrições devia apresentar um médico; no entanto os serviços só conseguiram providenciar 25. Essa situação era replicada com os enfermeiros portugueses, cujo número em falta atingia as quatro centenas de indivíduos, nem escapando a essa problemática o pessoal auxiliar de saúde africano O quadro de pessoal europeu e de auxiliares africanos dos SSHA era claramente insuficiente para "ocupar" e lidar com um território tão vasto e com uma população autóctone estimada em 3.500.000 indivíduos (Mora, 1924). ${ }^{8}$ 
Apesar da relevância da temática da saúde para representações do projecto colonial português apontada por Shapiro, a falta de um sistema de saúde estatal eficaz era apenas parte do problema, pois fatores relacionados com a exploração abusiva dos recursos humanos locais tinham impacto negativo no bem-estar das populações. A imposição de pagamento de impostos ao Estado; o trabalho forçado que não excluía nem mulheres ou crianças; as paupérrimas condições de vida e trabalho verificadas na maioria das empresas, tudo isso acompanhado por falta de alimentação e atenção sanitária para os trabalhadores, familiares e populações em geral, contribuíam para o decréscimo de população tangível desde as primeiras décadas do século XX. Isso mesmo foi verificado pelo professor de sociologia Edward Alsworth Ross (1925).

Em seu relatório para a Organização Internacional do Trabalho (OIT), o professor Ross revela as condições vivenciadas pelos africanos. Essas práticas abusivas eram amiúde sancionadas e/ ou mesmo perpetradas pela administração colonial. Em vez de proteger, o Estado explorava até mulheres e crianças, forçando-as a contribuir na construção de estradas e arranjar sua própria alimentação. ${ }^{9}$ Segundo Ross, os angolanos não tinham instrumentos para escapar a esse sistema, pois era a própria administração colonial que ajudava no recrutamento de trabalho-forçado e/ou praticava um regime quase escravocrata. As palavras de Ross (1925, p.59) são esclarecedoras: "governo não fornece praticamente nada para o povo das aldeias em termos de escolas, assistência médica, ajuda de emergência, ou justiça contra o comerciante branco como recompensa do pesado fardo da labuta não remunerada que recai sobre eles".

A avaliação e crítica de Ross iam para além de uma avaliação geral da ação de saúde pública do Estado. Os testemunhos recolhidos de vários atores históricos - pessoal de saúde, missionários, trabalhadores, mulheres, entre outros - caracterizam a inoperância dos serviços governamentais. A declaração de um médico numa missão religiosa é reveladora:

O serviço médico colonial tem um plano detalhado para colmatar as necessidades médicas dos nativos, mas que não tem sido posto em prática. Há apenas alguns médicos no interior, e estes estão muito dispersos. A sua atenção está centrada principalmente na prática clínica para brancos, e em geral, a ajuda médica não está disponível para o nativo. ... Em epidemias recentes de varíola e gripe, com altas taxas de mortalidade, que conheça não foram tomadas medidas de emergência (Ross, 1925, p.24).

Os angolanos respondiam a essa conjuntura de exploração desumana, insalubridade e falta de alimentação com fugas e deserções, o que se transformaria num problema de despovoamento da colónia. Ross (1925, p.34-35) descreve o deslocamento de missionários estabelecidos em Angola há 25 anos para o Congo Belga e Rodésia acompanhados por angolanos. ${ }^{10}$ No entanto, esse não era um episódio isolado, pois o processo de despovoamento do território persistiu até o final da década de 1940 quando Henrique Galvão ${ }^{11}$ (jan. 1947) o referiu num relatório confidencial apresentado em Lisboa a uma comissão da Assembleia da República.

O estudo de Perrings (1977) sobre mão de obra angolana a laborar nas minas de região de Katanga reforça a imagem de angolanos a fazerem escolhas racionais, a demonstrarem sua capacidade de agência, ao atravessarem a fronteira à procura de outras condições de vida e trabalho, permitindo um vislumbre sobre os processos de recrutamento e escolha entre dois 
territórios coloniais. Numa tentativa de colmatar essa situação, a administração colonial proibiu o recrutamento de angolanos para fora do território. Essa política tinha por objetivo a criação de uma reserva de mão de obra barata. No entanto, nos anos 1930, a imposição de políticas agrícolas de plantação de cash-crops (culturas agrícolas forçadas), como algodão, café ou tabaco, contribuiu para um decréscimo na produção agrícola e desvio da já fraca agricultura da produção alimentar (Heywood, 1987). Em última análise, foram os corpos e a saúde dos angolanos que mais sentiram a conjugação dessas várias políticas definidas na metrópole.

O relato do missionário canadiano Tucker (1927, p.178-179), referente ao período da década de 1910 à de 1940, em que esteve no Bailundo, confirma as descrições da vivência dos habitantes das áreas rurais presentes no relatório Ross:

Em certos lugares ao longo da costa, a peste bubónica é endémica, enquanto em outras regiões os animais são exterminados e os seres humanos sofrem com a temida doença do sono causada pela mosca tsé-tsé. A ancilostomíase é prevalente em toda a parte. A malária é, no entanto, o fator-chave na situação de saúde. Esta doença ... complica todos os casos médicos, especialmente problemas pulmonares, causando a morte a centenas de nativos durante o tempo frio de Junho e Julho. A varíola eclode constantemente em aldeias indígenas; a disenteria é comum, enquanto os leprosos vagueiam à vontade. Úlceras tropicais, filariose, conjuntivite, doenças oculares, bócio, vermes, doenças relacionadas com deficiências alimentares, problemas de estômago e outras enfermidades ainda não conhecidas flagelam as populações e retardam o desenvolvimento e capacidade plena dos corpos nativos. Muitos nativos lutam [para sobreviver] sob o peso de meia dúzia de doenças.

Até a meio da década de 1930 os angolanos que habitavam o Chitato experienciavam situação similar à verificada no resto do território. A distância entre os textos legais e a realidade era a mesma, quer fosse a disposição legal referente aos serviços de saúde de Angola ou o contrato entre o Estado e a Diamang, que outorgava responsabilidade à ultima pelo bem-estar das populações locais. A negligência e exploração por esses dois "atores" coloniais resultavam numa mesma consequência: estado de saúde paupérrimo tangível nos corpos africanos.

A vida para os africanos no Chitato não era pois exceção ao cenário dantesco verificado na colónia. Um depoimento do relatório Ross (1925, p.31-32), que refere o caso de um pai já idoso forçado a substituir o filho que desertara das minas de diamantes, tendo sido forçado a trabalhar "como um boi" a produzir tijolos, é claro sobre a similaridade entre as diferentes áreas da colónia. Esse exemplo denota o fardo do trabalho no Chitato para os corpos africanos, alguma capacidade de agência dos locais, mas também o poder (como conceito de Weber, 1978) ${ }^{12}$ colonial da companhia.

Como acima descrito, a exploração da mão de obra local pelo Estado e entidades privadas, incluída a Diamang, não respeitava género nem idade. Como nas obras públicas de construção de estradas, também nas minas a companhia diamantífera empregava trabalho infantil. As crianças tinham que suportar condições de trabalho similares às de outros trabalhadores, operando em horários similares, embora com tarefas mais leves, mas lutando contra as mesmas condições de vida precárias (Cleveland, 2010).

A Diamang seguia à risca o padrão de produção ao mais baixo custo da indústria mineira e uma medicina centrada nos ocidentais que operava no continente africano (Van Onselen, 
1975; Perrings, 1977; Patterson, 1981; Packard, 1989, Bell, 1999; Carstens, 2001; Ball, 2003). Seus trabalhadores labutavam sob condições péssimas: a alimentação era insuficiente, inconstante e a tempos mesmo inexistente; o alojamento tinha poucas condições de habitabilidade; não lhes era fornecida indumentária adequada para trabalho mineiro ou qualquer tipo de formação para esse efeito (Varanda, 2007, cap. 6). Como nas minas da África do Sul, a política da Diamang almejava à redução dos custos de produção ao mínimo, transferindo o fardo dos custos de doenças e da reprodução da mão de obra para as famílias e comunidades africanas, o que acarretava, direta ou indiretamente, um aumento de doenças nas áreas rurais, dentro ou fora da circunscrição do Chitato, onde a companhia recrutava (Packard, 1989).

Essa similaridade replicava-se também nos sistemas de saúde. Os serviços médicos da companhia - que nas primeiras décadas englobavam duas secções autónomas, SSD e as Missões de Profilaxia Contra a Doença do Sono (MPDS) - funcionavam em instalações sanitárias feitas de material perecível, adobe, tinham falta de pessoal, material hospitalar e debatiam-se com falta de veículos e infraestruturas rodoviárias. Até à sua reorganização em 1934, os SSD eram, portanto, o espelho na Lunda da sua congénere estatal, visível inclusive na similitude das queixas de ambos os diretores dos serviços. No caso do SSD, como no dos SSHA, o médico-chefe, doutor Vasques de Carvalho, escrevia à Direção Técnica de Bruxelas, alertando para a falta de médicos (Eggermont, Shaler, 12 jun. 1927). Os trabalhos dos médicos na Lunda, como nos SSHA, a juntar ao trabalho burocrático, incluíam a conceptualizaçao e supervisão da construção de instalações sanitárias. Assim, além da prática clínica, eles eram também arquitetos conceptualizando instalações sanitárias como hospitais e dispensários, faziam de mestres de obras, orientando trabalhadores locais nas construções ou improvisando quando faltava material de construção (Baptista, jun. 1925).

Tantos os SSHA como os dois ramos de saúde da Diamang (SSD e MPDS) concentravamse nas áreas urbanas, primordialmente onde se encontravam brancos. Enquanto as ações curativas dos serviços de saúde estatais concentravam-se nas principais cidades, os dois ramos dos serviços da companhia atuavam eminentemente nas instalações da companhia: espaços urbanos, industriais e minas, prestando particular atenção a empregados e quando os problemas de saúde o exigiam estendiam a assistência a trabalhadores locais. A localização das instalações sanitárias e a colocação de médicos e enfermeiros europeus (pessoal com melhor formação) seguia as regras do enclave, isto é, centralização dos recursos em áreas em que se encontravam brancos. ${ }^{13}$

As primeiras instalações sanitárias dos SSD localizavam-se no centro administrativo, Dundo, e seguiam a geografia produtiva dos diamantes, localizando-se nas áreas mineiras de Cassanguidi, Chingufo e Maludi. Em 1923 o engenheiro americano Gleen H. Newport (16 nov. 1923) notava que os hospitais do Dundo, Cassanguidi e Maludi, feitos de lama e madeira, estavam tão depauperados que deviam ser reconstruídos. Três anos depois é construído o primeiro hospital de tijolo, cimento e telhado de zinco - o hospital principal do Dundo. Mas, como em outras instalações, e em face da situação sanitária problemática, era usual nesses primeiros anos indivíduos serem hospitalizados em condições precárias, e o pessoal de saúde branco forçado a habitar as próprias instalações sanitárias devido à falta de alojamento (Carvalho, 1926, p.8). 
Nas duas décadas iniciais a Diamang não apresentou capacidade para ocupar sanitariamente a área contratual, não providenciando cuidados biomédicos de acordo com o contrato assinado, isto é, para todos os que trabalhavam para si ou os que viviam sob o seu "jugo". A definição do alvo principal da atenção dos SSD seguia o ditame racial da altura: preferência era dada aos empregados brancos. Os mineiros africanos, por norma, só recebiam cuidados curativos quando a produção diamantífera estava em perigo devido a epidemias e/ou se ocorresse uma incidência elevada de doenças e mortes. Os episódios da epidemia de gripe de 1918-1919, 1921 e 1922, todos diagnosticados pelo doutor Gillet, médico-chefe da companhia-irmã Forminière que operava a escassas dezenas de quilómetros do outro lado da fronteira, são reflexo de isso mesmo (Shaler, Brée, 4 jan. 1922). ${ }^{14}$ A falta de alojamento e de indumentária adequada, a escassez de alimentos e de uma rede de suporte familiar, juntamente com um trabalho manual extenuante, efetuado sob as mais diversas condições atmosféricas - calor tórrido ou chuva tropical - marcavam os corpos e biografias de milhares de africanos.

Os registos de saúde revelam que em 1935 metade da mão de obra da companhia foi hospitalizada com problemas relacionados com o trabalho nas minas e/ou com más condições de vida. No topo da lista de causas de morte estavam complicações do trato respiratório com quase $60 \%$, seguidas por doenças digestivas e intestinais (disenterias e diarreias). A existência de causa de morte de astenia (corolário do esforço físico e da parca alimentação) confirmava que a situação assustadora descrita por Ross e Tucker para outras áreas da colónia era replicada no Chitato (Picoto, 1935). Mas ao invés desses autores, os relatórios de saúde da companhia omitiam as condições de vida (alojamento, alimentação e saneamento), de trabalho (vestuário e segurança no trabalho) e os parcos cuidados de saúde fornecidos pela Diamang (Carvalho, 1926, p.1-13), culpando antes as vítimas (doentes e mortos) pela situação, recorrendo a caracterizações simplistas de falta de higiene das aldeias, aversão à biomedicina vis-à-vis ao favorecimento de medicinas tradicionais.

Num outro extremo da colónia a situação não era melhor. Enquanto a dificuldade da Companhia Agrícola do Cassequel em recrutar africanos com boa robustez física para o trabalho indiciava a dureza da vida para a população em geral (Ball, 2003, p.178), a companhia seguia as directrizes da administração metropolitana, que desrespeitavam a legislação referente à contratação de um médico em permanência, pois era rentável enviar os trabalhadores doentes para hospitais públicos, também estes mal-equipados e com quadros insuficientes de pessoal. No entanto, a "sorte" dos africanos não melhorava durante seu contrato. A negligência da Cassequel resultou terreno fértil para a disseminação de doenças. Nos anos 1920 a taxa de hospitalização dos trabalhadores ultrapassava os 40\%, e a de mortalidade dos internados atingia os 15\% (Esteves, 1999, p.585). Na visita à companhia em 1926, o diretor dos Negócios Indígenas, Álvaro Lopes Figueira (citado em Esteves, 1999, p.587), nota que "a assistência médica e as precauções higiénicas que a Cassequel providenciou aos seus trabalhadores deixam muito a desejar". Situações que levaram a uma epidemia de febre tifoide que dizimou 7\% da mão de obra (324 trabalhadores), verificando-se outras epidemias em 1941 e 1942 sublinhando as consequências das políticas de produção de baixo custo (p.585).

Infelizmente os Caminhos de Ferro de Benguela não eram exceção. Em 1914 eles apresentavam somente 12 camas para 902 trabalhadores, mantendo-se em 1921 as 12 camas 
para 2.100 trabalhadores e respectivos dependentes, só aumentando na década de 1950 o número de camas para 71 camas para um total de dez mil trabalhadores (Esteves, 1999, p.584-587). Apesar de problemática a situação verificada na rede sanitária dos SSD em 1930, esta apresentava já cerca de três dezenas de instalações sanitárias - dispensários e postos de socorro perto das áreas de mineração ou "urbanas". Com o rácio de um médico para 1.750 africanos e uma cama por 34 indivíduos, a companhia publicitava os seus serviços de saúde. No entanto, essas estatísticas estavam longe de representar a realidade, pois era comum faltarem camas, forçando doentes africanos a ocupar zonas indevidas ou dormir ao relento (Almeida Sousa, 4 dez. 1930).

Se na década de 1930 os SSD apresentavam corpo de pessoal insuficiente em face do número crescente de explorações mineiras, da situação de inércia do Estado e das várias companhias privadas, não era de admirar que apesar dos problemas no Chitato a ação dos SSD fosse considerada pelo governo positiva. ${ }^{15}$ No início dos anos 1930, o governador-geral da colónia, coronel de infantaria Eduardo Ferreira Viana, exaltava o trabalho da companhia:

pela excelente organização dos seus serviços médicos e pela assistência cuidadosa, persistente e tecnicamente eficaz prestada não somente ao seu pessoal europeu e indígena, como a toda a população da vasta região onde está instalada a sua exploração mineira, incluindo funcionários civis e militares, tanto no serviço ambulatório de reconhecimento como nas excelentes formações hospitalares que possui (Angola, 27 out. 1934).

No entanto, nessa mesma altura, em 1933-1934 o vislumbre de uma epidemia de doença do sono diante do aumento brusco do número de casos verificado pelas MPDS despoletou a reorganização dos serviços médicos da Diamang. Mas, mais importante do que essa reforma para a saúde dos trabalhadores e populações locais foram as alterações relativas à segurança alimentar encetadas pela Diamang e a modificação do cariz dos programas de saúde pública dos SSD que enfatizariam ações preventivas. Essas medidas contribuíram para o "descolar" das condições de vida e sanitárias no Chitato vis-à-vis aos das suas congéneres - estatais, Cassequel, CFB.

\section{"Medicina colonial" fragmentada: Serviços de Saúde da Companhia de Diamantes de Angola e outros serviços de saúde, 1935-1945}

Até meio da década de 1930 tantos os SSHA como os dois ramos dos serviços de saúde da Diamang (SSD e MPDS) concentravam-se nas áreas "urbanas", primordialmente onde se encontravam brancos. No entanto, nesses anos que a Diamang abandona a medicina de enclave e algumas das políticas de baixo custo, adotando uma abordagem mais preventiva e estendendo a prestação de cuidados à totalidade da área contratual e a suas populações, quer tivessem ou não relações laborais com a companhia.

Apesar de o lucro permanecer sua raison d'être, o receio de epidemias, a necessidade de atentar à reprodução da mão de obra indígena e ideias relativas à produtividade forçaram a Diamang a prestar mais atenção à sua mão de obra, composta por um reservatório de população local e migrante. Durante essa década os cuidados de saúde - assistência médica curativa e preventiva - foram sistematizados para os trabalhadores alargados para as suas famílias e os estranhos (população local sem relação produtiva com a companhia). 
O crescimento do sistema de saúde foi exponencial, para além da área contratual, cobrindo território de $28.000 \mathrm{~km}^{2}$. Essa transformação recebeu impulso acrescido em termos de programas preventivos quando da alteração da Direção Técnica da Lunda para Direção-geral da Lunda. De uma visão eminentemente produtiva vigente até ao final da década de 1930, o primeiro diretor-geral, Tavares Paulo, na década de 1940 passou a enfatizar políticas sociais (David, 27 jan. 2004; Matos, 15 dez. 2004). Essas novas ações preventivas eram realizadas por pessoal africano supervisionado, ou não, por enfermeiros europeus. Essa mudança concretizou-se na expansão dos serviços para áreas rurais, primeiro com "horizontalização" das campanhas MPDS, que além da doença do sono passaram a incluir cuidados maternoinfantis, parasitismo intestinal), seguindo-se com estabelecimento de instalações permanentes, que incluiriam maternidades e laboratórios farmacêuticos.

Nos anos 1940 os antigos hospitais (Dundo, Andrada, Maludi, Cassanguidi) foram remodelados, recebendo instalações para parturientes e pediátricas, apresentando os dois primeiros, rotulados como hospitais centrais, em 1955, bloco operatório com ar-condicionado, cozinhas, refeitórios, lavandarias e novos instrumentos como raios- $\mathrm{X}$, radioscopia, ultravioleta, ultrassom, máquinas de diatermia e eletrocardiogramas. ${ }^{16}$ Mantendo o encalce na geografia produtiva dos diamantes, novas instalações hospitalares, de tijolo e cimento, foram edificadas em zonas mais distantes, por exemplo, em Facaúma (hospital-dispensário) e perto dos postos administrativos de Lóvua, Sombo, Cachimo e Luia (dispensários). Os recursos humanos foram também alvo de profundas modificações. De três médicos em 1936, localizados no Dundo e Andrada, portanto de acordo com particular atenção para brancos e ao pessoal dos grupos mineiros de Andrada, Cassanguidi e Maludi, atingiu-se 14 em 1955, três dos quais trabalhavam nas equipas ambulantes. O facto de o pessoal europeu de enfermagem não replicar esse crescimento (dos dez enfermeiros europeus e uma parteira existentes entre 1936 e 1946, aumentaram para 24 em 1955, mantendo-se a única parteira) deveu-se à política de africanização dos SSD (Carvalho, 1936, p.2; Picoto, 1955). O aumento exponencial do pessoal auxiliar africano, de 49 indivíduos para mais de quinhentos em 1955 reflete a importância desses auxiliares nas políticas de saúde pública da companhia. ${ }^{17}$

Apesar da reorganização dos SSHA de 1919, dos avisos do doutor Damas Mora em 1921 e do relatório Ross em 1925, não houve alterações profundas na prestação de cuidados biomédicos. Em 1936 foi a vez do doutor Ferreira dos Santos apontar as dificuldades sentidas nos territórios coloniais, nomeadamente na vertente de prevenção (Santos, 1936). O relatório do SSHA referente a 1937 levanta o véu dos problemas encontrados a nível local. No interior da colónia, no distrito de Malange, que à data abrangia a área do distrito da Lunda, quase $80 \%$ dos tratamentos foram realizados pela Diamang que tinha a seu cargo $10 \%$ da área desse distrito (Angola, 1940, p.6). Uma situação que tinha consequências diretas na saúde das populações, nomeadamente no interior da colónia.

Na Cassequel a situação era ainda mais problemática. A companhia de Benguela apresentava em 1937 três profissionais com formação universitária: um médico, um farmacêutico/ enfermeiro e um enfermeiro, que eram coadjuvados no tratamento de trabalhadores por três auxiliares locais "especializados". Enquanto o pessoal português com formação superior assistia os quatrocentos ocidentais, os auxiliares africanos tinham a seu cargo cerca de cinco mil trabalhadores e respectivas famílias, que, até ao final da década 1940, tinham que pagar 
pelos cuidados de saúde. Essa falta de investimento na saúde dos trabalhadores concorreu para as situações epidémicas, como atrás mencionado, nos anos de 1941 e 1942 (Ball, 2003, p.182). A parcimónia de cuidados médico-sanitários estatais é reforçada pela leitura do $A n$ African Survey, de lord Hailey (1938, p.1182): "Há poucas provas de que algum trabalho na saúde esteja a ser feito nas áreas rurais numa escala comparável com as ações dos governos francês ou belga".

No resto da colónia os anos 1930 e 1940 representaram o ponto mais baixo no que concerne à falta de segurança alimentar básica. Jill Dias (1981, p.375-376) aponta vários fatores que contribuíram para maior implementação colonial e afetaram produção agrícola, alimentação e consequentemente a saúde das populações locais. A imposição na práxis das leis anticaça de 1910 reduziu o acesso por parte das populações nativas a proteínas animais, o que, acompanhado com as políticas de cash-crops, uma "preferência" por uma dieta com base na mandioca, alimento nutricionalmente pobre, e um desvio dos parcos recursos familiares para a aquisição de bebidas alcoólicas, contribuiu para uma alta prevalência da malnutrição por todo o território até a meio do século XX. A esse problema juntavam-se uma alta taxa de mortalidade infantil, a persistência de malária e doenças parasitárias, respiratórias e venéreas, e acidentes de trabalho que chegavam a atingir cerca de $40 \%$ da mão de obra em fazendas ou companhias como a CFB. Esse cenário continuava a empurrar muitos africanos para o êxodo da colónia como "forma de protesto" contra políticas e o maior jugo colonial (Dias, 1981, p.376-377; Esteves, 1999, p.580-593). ${ }^{18}$ Se as condições de vida não melhoravam em grande parte da colónia, o mesmo acontecia em relação aos SSHA.

Enquanto as décadas de 1930 e 1940 foram marcadas por uma crise financeira internacional acutilante que teve clara influência negativa na vida das populações locais, com alterações verificadas no contexto político internacional, onde sopravam com mais acutilância novos ventos de descolonização, as décadas seguintes seriam marcadas por uma atenção crescente às populações locais e uma constante representação dessas ações no palco político internacional.

\section{No contexto da Guerra Fria, 1945-1975}

O final da Segunda Grande Guerra despoletou alterações na hierarquia das potências internacionais com as novas potências EUA e URSS a ganharem proeminência em face da Grã-Bretanha e França, e abriu as portas ao processo de descolonização. Esse novo contexto empurrou o Estado Novo para novas reorganizações dos serviços de saúde que centralizariam a organização e definição de políticas de saúde, pelo menos em teoria, em Lisboa, ao mesmo tempo que se reforçavam as representações de uma obra civilizacional particular de Portugal.

Dois anos após o término da Segunda Guerra Mundial, em 1947, Henrique Galvão rotulou essa reestruturação como meramente académica. Galvão, então inspetor da colónia, percorreu o território do interior afastando-se portanto dos usuais centros urbanos, localizados na costa. No "mato" ele se deparou com um vazio, vastas áreas sem vestígios de presença administrativa colonial, incluindo a ausência de instalações de saúde para as populações autóctones: "Não encontrei qualquer unidade sanitária estatal ao longo de milhares de quilómetros percorridos pelo interior ... nada ... absolutamente nada digno de respeito, admiração ou qualquer valor" (Galvão, jan. 1947, p.23). 
Durante as décadas de 1940 e 1950 os serviços médicos do Estado continuavam a lutar contra orçamentos exíguos e quadros de pessoal e instalações insuficientes. Em meados da década de 1940, os SSHA persistiam a não pôr em prática a proclamada "atenção e proteção ao indígena". Até a década de 1950, em todo o interior de Angola, várias cidades e vilas apresentavam um número reduzido de unidades de saúde, muitas vezes chefiadas por enfermeiros, em vez de médicos. Se nas zonas urbanas o sistema de saúde era quase inexistente, nas áreas rurais das circunscrições era ainda mais problemático. Havia casos de localidades sem instalação de saúde estatal, onde tratamentos e medicamentos eram fornecidos pelo pessoal administrativo, usualmente o chefe de posto (Esteves, 1999, p.590). ${ }^{19}$

As populações locais por norma recorriam aos sistemas médicos tradicionais, e somente quando os resultados eram insatisfatórios recorriam aos cuidados biomédicos, preferencialmente às missões - católicas e protestantes (Redinha, 1975; Areia, 1990). As missões religiosas - católicas e protestantes - continuavam a ser o "último" recurso para africanos enfermos. Os serviços prestados nessas missões foram qualificados por Mário Costa (14 jul. 1950), agente de recrutamento da Diamang na Lunda, como de fraca qualidade, afirmando mesmo que muitos dos enfermeiros deviam ser considerados auxiliares sanitários em face dos parcos conhecimentos que tinham.

Uma análise à CFB cuja área de influência se estendia do Lobito até a leste de Angola permite verificar que o setor privado era pouco melhor. Sobre a assistência sanitária na área de influência do CFB o historiador angolano Emmanuel Esteves (1999, p.592) é peremptório: não era boa. A imagem transmitida é similar à dos serviços estatais: escasseavam médicos, não havia consultas regulares, sendo muitos dos postos de saúde dirigidos por pessoal auxiliar africano, existindo outros despojados de qualquer pessoal de saúde (p.589). Somente na década de 1950 a companhia investiu na melhoria dos seus serviços de saúde com a construção de hospitais no Olupito e Vila Luso e em ambulâncias para trabalhadores africanos, enquanto, segundo Esteves (p.582), edificava uma estância termal para brancos.

Essa bitola enviesada para o pessoal branco era replicada em várias companhias. A Cassequel regia-se em padrão semelhante, só investindo na assistência médica após pressão governamental exercida depois da Segunda Guerra Mundial (Esteves, 1999, p.584). Os relatórios da Companhia de Cabinda e da Companhia do Açúcar de Angola parecem enfatizar a existência de um "consenso" entre diversas companhias coloniais relativamente ao não investimento em cuidados biomédicos durante grande parte do período colonial do século XX (CdC, 1957; CdAA, 1941).

Uma vez mais, a realidade no terreno relativamente às condições de vida e em particular à prestação de cuidados biomédicos favorecia os SSD em face dos SSHA ou outras companhias privadas importantes - CFB e Cassequel. Daí a impressão muito positiva que continuavam a causar nos elementos governamentais que visitavam o Chitato. Em 1945 foi a vez do ministro das Colónias, Marcelo Caetano, louvar os cuidados dispensados pela empresa aos seus trabalhadores, em termos de alimentação e saúde, algo que segundo o ministro era visível nos rostos e corpos dos trabalhadores (Diamang, 1946, p.9). Uma breve atenção para os serviços estatais na Lunda é elucidativa da "admiração" do ministro quanto aos serviços prestados pela Diamang. 
Em 1950 o agente de recrutamento da companhia em Henrique de Carvalho (capital da Lunda) referia que o minúsculo quadro dos SSHA era claramente insuficiente para prestar cuidados a uma população estimada em meio milhão, espalhada ao longo de $228.000 \mathrm{~km}^{2}$ (Costa, 14 jul. 1950). Segundo Mário Costa a falta de cobertura sanitária estatal era tangível nos 85\% de mortes atribuídas a causas desconhecidas (19.237 do total de 22.477 óbitos registados pelo SSHA). Essa percepção de uma situação dramática foi reforçada numa entrevista com o doutor António Bellini Jara (2 mar. 2004), médico dos SSHA, que na década de 1950 notava que "era o único médico no distrito da Lunda, enquanto os SSD tinham 15 médicos somente na sua circunscrição".

Em 1957, esse hiato de investimento foi quantificado pelo novo médico-chefe dos SSD, doutor José Henriques Santos David. Enquanto os SSD apresentavam 72 instalações de saúde, o Estado numa área 17 vezes maior do que o Chitato, dispunha de 320, em detrimento das 1.200 que a relação territorial impeliria. A acutilante da diferença existente entre serviços verificava-se também nos rácios de médicos e enfermeiros por número de habitantes. Os SSD apresentavam um rácio de um médico por cada cinco mil habitantes e de um enfermeiro por cada 2.500 habitantes, enquanto nos SSHA, quatro anos antes, em 1953, o rácio era de um médico para 26.556 habitantes e um enfermeiro para 11.970 habitantes (David, 1957, p.12-13). Uma disparidade que o doutor Jara (2 mar. 2004) afirmava ser replicada em relação ao pessoal africano auxiliar de saúde.

A diferença entre esses dois atores coloniais teve como corolário um acerto de agendas; o estado colonial continuaria a preterir territórios contíguos às zonas de exploração diamantífera e recrutamento para uma administração sanitária privada pela Diamang. A área de ação dos SSD continuava a ultrapassar o que fora contratualmente definido em 1921, ocupando no final do período colonial um espaço equivalente à metade da área da metrópole política. Os SSD tinham dificuldades crescentes para contratar pessoal europeu, médicos e enfermeiros (particularmente após o início do conflito bélico de libertação), e para atenuar a insuficiência de leitos para hospitalização - longe dos 2.720 recomendados internacionalmente; além disso, o consequente aumento da população tornava difícil que se abrangessem as necessidades de saúde que os mais de cem mil habitantes "requeriam" de um sistema de saúde (Varanda, 2007, cap. 3).

Apesar das contrariedades, qualquer comparação com os outros serviços biomédicos ativos na colónia era benéfica para os SSD. Em 1960 enquanto, a Diamang apresentava 210 atos de assistência por dia, a Cassequel ficava-se pelos cinquenta. ${ }^{20} \mathrm{Em} 1968$ enquanto os SSHA realizaram 8.250.00 atos de assistência numa população de aproximadamente 5.800.00 indivíduos, os SSD apresentavam 3.209.182 para uma população de quase cem mil pessoas (Shapiro, 1983, p.165-166; Varanda, 2007, cap. 3). A favorabilidade das comparações mantinha-se mesmo quando se tratava do ator Estado, reforçando portanto o carácter único dos serviços de saúde da diamantífera num contexto de sobrevivência cada vez mais problemático para o projeto colonial português.

As diferenças verificadas entre as décadas de 1920 e 1950 eram notáveis com o SSD a ocupar sanitariamente sua região, zonas rurais incluídas, e a prestar cuidados biomédicos contratualmente definidos. Apesar dos melhoramentos, em 1955, muitas das instalações sanitárias requeriam melhoramentos, e o número de camas (744) revelava-se insuficiente 
em face do número crescente de africanos a necessitarem de internamento (Picoto, 1955). Dito isso, permaneciam a hierarquia rácica e as condicionantes geoprodutivas de diamantes vigentes desde as primeiras décadas de atividade da companhia, algo que mesmo após 1961, no seguimento do fim do regime do indigenato pelo ministro Adriano Moreira, a assistência não era igual para todos: centrava-se nos ocidentais, seguido pelos trabalhadores e respectivas famílias, deixando à margem a maior parte da população do Chitato (Varanda, 2012).

Apesar de persistirem problemas de saúde, como a malária e doenças respiratórias - que afetavam trabalhadores e habitantes -, a redução de incidência de parasitoses intestinais, varíola e doenças sexualmente transmissíveis e acidentes de trabalho contribuía para reforçar a imagem dos SSD como um caso à parte no panorama imperial português. Essa ideia era também perceptível pelo regime, que usava esses serviços para melhor consubstanciar as representações coloniais em fóruns internacionais. A centralidade e a importância do exemplo da Diamang nos relatórios das décadas de 1960 e 1970 da Organização Internacional do Trabalho (OIT) e da Organização Mundial da Saúde (OMS) ilustram esse argumento.

\section{O projeto colonial e a saúde nos "palcos" internacionais}

Da década de 1950 em diante, a OIT perscrutava as condições laborais e de vida dos trabalhadores. Outras organizações internacionais como a Organização das Nações Unidas (ONU) e a OMS perscrutavam a situação experienciada nos territórios coloniais portugueses. Essas investigações foram feitas não só através da produção de relatórios político-académicos (elaborados nos gabinetes de várias metrópoles por compilação da informação existente), mas, nos casos da OIT e OMS, incluindo visitas ao terreno com avaliação da situação in loco.

Em 1952 o relatório da OIT centrava-se na existência de trabalho forçado, ilustrando o caso das exigências físicas da exploração diamantífera sobre a mão de obra. Como maior empresa da colónia a Diamang estava presente, sendo visada pelos inspetores, que notaram sua influência negativa, direta ou indiretamente, nas condições de vida da população ativa (ILO, 1953, p.319). Se no nível internacional a companhia era, portanto, alvo de críticas, no nível da colónia nesse mesmo ano, Ernesto de Vilhena mostrava seu contentamento com o trabalho dos SSD, anotando à mão, no relatório referente ao ano de 1952, "que a companhia devia ser considerada ... uma instituição de bem público". Essa afirmação relacionava-se com a "eterna" comparação com os serviços do Estado e de outras companhias, que "ano após ano" era favorável à Diamang. ${ }^{21}$

A OIT foi um dos palcos internacionais em que os serviços de saúde prestados pelos colonizadores eram usados para trunfo em face de crescente coro anticolonial. Se no relatório da OIT referente à visita de 1951 dos inspetores da organização à Lunda, esta um ator colonial visado, entre muitos outros, nos relatórios ulteriores (1961 e 1971), o papel da companhia modificou-se. Nestes dois últimos a função da Diamang era de "testemunha abonatória" do projeto colonial português (ILO, 1962, p.58-66), ou seja, o exemplo perfeito da ação civilizadora colonial portuguesa. Apesar de os relatórios da OIT se centrarem nas condições de trabalho, os textos referem também as condições de vida e, indiretamente, a prestação de cuidados de saúde no Chitato (ILO, 1971). A alteração da "vocação" da Diamang e a importância dos serviços biomédicos - curativos e preventivos - prestados pelos SSD reforçam a diferença 
tangível no terreno entre os diversos sistemas de saúde, estatais e de outras companhias privadas, e o papel central deles na construção das representações coloniais.

No entanto, a ONU era o palco principal em que o governo precisava defender mais amiúde o projeto colonial em face dos diversos comités que escrutinavam a África portuguesa. Shapiro (1983, p.309) mostra como a prestação de cuidados biomédicos ganhou centralidade nesses debates principalmente a partir de 1960, intentando-se que os programas de saúde fossem prova do "altruísmo português, da sua competência e eficácia enquanto povo colonizador", ou seja, reforçando os direitos portugueses para prolongar o seu projeto colonial.

Um dos ataques mais acutilantes surgiu em 1961 no Comité Especial para os Territórios Administrados por Portugal, das Nações Unidas. Entre diversas temáticas abordadas, estava uma apreciação muito negativa dos serviços de saúde das colónias. O rol de críticas incluía escassez de recursos, falta de instituições de formação superior de profissionais de saúde (médicos, farmacêuticos, enfermeiros, parteiras e agentes de saúde), estatísticas pouco credíveis, e tratamento diferencial para brancos e locais (Shapiro, 1983, p.314-315). O Programa Especial de Formação para os Territórios Administrados por Portugal, aprovado no ano seguinte, 1962, pela mesma organização, intentava colmatar a falta de formação do pessoal auxiliar de saúde, mas os resultados foram escassos (p.320).

Numa tentativa de contrabalançar essa visão negativa, Portugal recorreu à OMS para avaliar os serviços de saúde coloniais. Os médicos ao serviço da OMS Ernani Braga (Brasil), Ruperto Casanueva (Chile) e Jean-Simon Cayla (França) classificaram, no cômputo geral, os serviços de Angola e Moçambique como aceitáveis, e a medicina preventiva na Guiné muito boa (Relatório..., 1963, p.115-122). O relatório referia a necessidade de melhorar a assistência médica em áreas rurais e de investir na formação em saúde de pessoal local. Em julho de 1962 o doutor Jean Cayla visita o Chitato, possibilitando ao governo usar a Diamang como uma sinédoque para o resto da colónia/império. A avaliação considerou os SSD excelentes, o que, por sinédoque, se refletiria na conceptualização dos serviços de saúde privados em Angola. Os resultados não foram mais negativos porque a comparação fora efetuada com os novos países independentes, dilapidados de pessoal com mais formação que, com a independência, retornara às respectivas metrópoles.

Em 1965, com Portugal excluído do Comité Regional Africano da OMS, a Diamang mais uma vez tinha papel-chave para as representações coloniais de um império que cuidava das suas populações nativas. Dessa feita foi perante uma equipa de médicos ao serviço da Fundação Rockefeller, constituída pelos doutores K. Kokernot e B. Worth, interessada no combate à febreamarela. Nesse mesmo ano a companhia publicou um livro - Alguns aspectos da assistência médico-sanitária no Concelho do Chitato (David, 1965) -, cujos textos, estatísticas e também imagens deixavam uma mensagem clara: a missão civilizadora, com o cariz sanitário, estava a ser científica e exemplarmente levada a cabo. As ações dos SSD num canto da colónia chegavam facilmente à arena da política internacional, um facto de cuja relevância o pessoal de saúde europeu estava consciente.

Os relatórios da OIT e da OMS ilustram bem o entrelaçar entre os SSD e a imagem colonial/ imperial. A ineficácia do sistema de saúde estatal empurrou o governo, até à independência, a recorrer aos SSD como exemplo dos cuidados portugueses. A Diamang teve um papel central na produção de representações coloniais encetada pelo regime do Estado Novo que 
reforçavam o discurso lusotropicalista de um colonialismo único, de cariz atencioso para com as populações locais (Castelo, 1998). Assim, um dos cantos mais remotos do império era colocado na rota de visitas políticas, era pedido à empresa que respondesse a diversos inquéritos internacionais, citando-se amiúde a companhia como exemplo da prestação de bons cuidados biomédicos portugueses.

\section{Considerações finais}

Uma análise comparativa das práticas biomédicas de vários atores coloniais revela claras diferenças entre a prestação de cuidados. Durante as quase seis décadas de atividade da Diamang, os SSD foram recorrentemente caracterizados como um caso ímpar na colónia. Se nas primeiras quase duas décadas de atividade tal não era o caso, após a reorganização dos SSD e MPDS num único serviço, a par de medidas agroalimentares para garantir a segurança alimentar na área, fizeram com que o panorama se modificasse nas décadas de 1930 e 1940. Um investimento constante, relacionado com o éthos de colonialismo científico, e a disponibilidade orçamental crescente fizeram com que os SSD se tornassem num caso à parte em termos de investimento nos serviços de saúde. Essa diferença é tangível em termos de morbimortalidade em Angola, mais vincada a partir de metade dos anos 1930, e foi aproveitada pelo regime colonial nos fóruns internacionais para desacreditar a maré de argumentos pró-descolonização.

Se imagens dos africanos como "esqueletos vivos" (Dias, 1981, p.377) se mantiveram década após década, as representações coloniais relativamente a um império cuidador de suas populações também persistiam. Estas últimas, estando em claro desacordo com a realidade vivenciada no terreno, eram apenas imagens quixotecas que "clamavam" pela manutenção do projeto imperial português em fóruns internacionais, em que há muito desvanecera o paradigma imperial.

\section{AGRADECIMENTOS}

Investigação possibilitada pelos financiamentos resultantes da bolsa de pós-doutoramento SFRH/ BPD/30439/2006 (2010-2012) e projeto PTDC/AFR/100646/2008 (2010-2012) ambos da Fundação para a Ciência e a Tecnologia, Portugal. Agradeço à Direção e ao pessoal do Museu de Antropologia da Universidade de Coimbra, particularmente ao professor Nuno Porto, por me facilitarem o acesso aos arquivos da Diamang.

\section{NOTAS}

\footnotetext{
${ }^{1}$ Aqui segue-se a denominação apresentada por Clarence-Smith (1985).

${ }^{2} \mathrm{O}$ uso do termo morbilidade refere-se a diagnósticos de doenças, e de mortalidade a causas de morte e respectivos números.

${ }^{3}$ Enquanto John Farley (1991) recorre a estudo epidemiológico para desenvolver o conceito de medicina imperial, autores como Bell (1999), Hewa (1996) e Manderson (1996) reivindicam a colónia como o espaço "natural" para a prestação de cuidados biomédicos no império.

${ }^{4} \mathrm{O}$ uso da expressão populações locais, bem como dos termos africanos ou angolanos, contém a percepção da variedade da população em termos étnicos, sociais, geracionais etc.

${ }^{5}$ Conferência que decorreu entre novembro de 1884 e fevereiro de 1885 e na qual as potências imperiais europeias acordaram entre si as divisórias dos territórios africanos.

${ }^{6}$ No início do século XX prospetores da empresa Belga Forminière (Société International Forestière et Minière du Congo) descobriram diamantes nos territórios contíguos ao nordeste angolano, circunscrição
} 
do Chitato. Para mapear jazigos de diamantes criou-se a em 1911 a Pesquisas Mineiras de Angola que deu lugar em 1917 à Diamang que exploraria os jazigos mapeados. Sobre a relação entre Forminière e Diamang desde sua génese até os anos 1940, ver Varanda (2011).

${ }^{7}$ Para uma resenha em jeito de fac-simile referente à situação dos cuidados médicos e legislação sobre a saúde em Angola entre os séculos XV e XIX, ver Walter (1953).

${ }^{8}$ Cada posto administrativo devia contabilizar dez "enfermeiros" locais, um número que os serviços falhavam redondamente de colmatar. Passadas quase três décadas, discussões sobre os auxiliares locais de sáude ainda persistiam.

${ }^{9}$ É vasta a bibliografia referente ao trabalho forçado. Uma das coletâneas mais recentes é a da Universidade do Porto (Ceaup, 2009).

${ }^{10}$ Esses são acontecimentos que devem ser inscritos com significados, como escolhas racionais ou respostas, em face de uma existência forçada num perigoso ambiente de trabalho e de vida (Van Onselen, 1975).

${ }^{11}$ Galvão fora nos anos 1930 um dos grandes ideólogos do Estado Novo, mas nos anos 1940 passou a ser um o inspetor-chefe das colónias, experiência que talvez o tenha feito rever suas posições, tornando-o num dos principais críticos, sendo o sequestro do navio Santa Maria, em janeiro de 1961, um dos principais atos políticos a atingir visibilidade internacional para o caso português.

${ }^{12}$ Considerado como a probabilidade de um ator dentro de uma relação social estar em condições de realizar sua própria vontade apesar da resistência. Para mais informação ver Weber (1978, chapter 1).

${ }^{13}$ Subjacente ao uso do termo enclave está o conceito de "medicina de enclave" avançado pelo historiador britânico Arnold (1993).

${ }^{14}$ Para mais informações sobre a génese dessas empresas e as suas relações transcoloniais, ver Varanda (2011).

${ }^{15}$ No início da década de 1930 havia aumento para quase três dezenas de instalações sanitárias perto de zonas de exploração diamantífera ou de produção agrícola (Carvalho, jan. 1930).

${ }^{16}$ Sobre as redes extraimperiais usadas pelas companhias, ver Varanda (2010).

17 Os ajudantes de saúde de ambos os sexos estavam dispersos por vários serviços e instalações: postos sanitários, equipas móveis contra a doença do sono e materno-infantis e laboratório. A literatura relativa à importância do pessoal local auxiliar de saúde na "tradução" e melhor aplicação da biomedicina em África vai sendo vasta; ver, por exemplo, Derrick (1983), Hunt (1999), Eckert (1999), Kumwenda (2006), Lawrance, Osborn, Roberts (2006) e Dionne (2011).

${ }^{18}$ Percentagem verificada por Galvão (jan. 1947). Situações similares foram descritas em diversos contextos coloniais: África do Sul (Packard, 1989); Rodésia do Sul (Van Onselen, 1976); Rodésia do Norte, (Perrings, 1977); Congo Belga (Lyons, 1991).

${ }^{19}$ Nem mesmo os Planos de Fomento I, II e III, implementados na década de 1950, contemplaram o investimento na saúde africana.

${ }^{20}$ Apesar de ser difícil estabelecer a definição referente a atos de assistência empregues pelos diferentes atores coloniais, a comparação em lato sensu ilustra a diferença de prestação de cuidados de saúde.

21 "Creio que bastaria este relatório para a Companhia poder ser considerada uma 'instituição de utilidade pública', e rebater muita das acusações que lhe são feitas por ignorantes ou mal intencionados" (Vilhena citado em Picoto, 1950, s.p.).

\section{REFERÊNCIAS}

ABRANCHES PINTO, Guilherme A.A.

Serviços de Saúde de Angola: esboço histórico. Dissertação (Licenciatura) - Instituto Superior de Ciências Sociais e Política Ultramarina, Lisboa. 1967.

ALMEIDA SOUSA, A.A. de.

Missões de Profilaxia Contra a Doença do Sono, relatório n.2. Arquivo da Diamang. Direcção Administrativa. Serviços de Saúde. Relatórios anuais (Doença do Sono: 1934-1955); (Serviço de
Saúde: 1926, 1932-1935, 1940-1952). (Museu de Antropologia da Universidade de Coimbra, Coimbra). 4 dez. 1930.

ANGOLA.

Boletim Oficial de Angola, n.43, 27 out. 1934.

ANGOLA.

Direcção dos Serviços de Saúde e Higiene de Angola. Boletim Sanitário de Angola: relatórios estatísticos de 1937-1938. Luanda: Imprensa Nacional de Angola. 1940. 
AREIA, Manuel Laranjeira Rodrigues de. Contribution to the study of cultural dualism in medical practices. In: Chaudhuri, Buddhadeb (Ed.). Cultural and environmental dimension on health. Delhi: Inter-India Publications. p.124-130. 1990.

AREIA, Manuel Laranjeira Rodrigues de. Les symboles divinatoires: analyse socio-culturelle d'une technique de divination des Cokwe de l'Angola: Ngombo ya Cisuka. Coimbra: Instituto de Antropologia/Universidade de Coimbra. 1985.

ARNOLD, David.

Colonizing the body: state medicine and epidemic disease in nineteenth-century India. Berkeley: University of California Press. 1993.

ARNOLD, David.

Introduction: disease, medicine and empire. In: Arnold, David (Ed.). Imperial medicine and indigenous societies. Manchester: Manchester University Press. 1988.

BALL, Jeremy.

The colossal lie: the Sociedade Agrícola do Cassequel and Portuguese colonial labor policy in Angola, 1899-1977. Dissertação (Doutorado) University of California, Los Angeles. 2003.

BAPTISTA, Calisto Martins.

Relatório de saúde. Arquivo da Diamang. Serviços de Saúde. Pasta 126B,9-1º relatórios médicos, de 21 nov. 1921 a 31 jul. 1927 (Museu de Antropologia da Universidade de Coimbra, Coimbra). jun. 1925.

BELL, Heather.

Frontiers of medicine in the Anglo-Egyptian Sudan, 1899-1940. Oxford: Clarendon Press. 1999.

BIRMINGHAM, David.

Empire in Africa: Angola and its neighbours. Athens: Ohio University Press. 2006.

CADORNEGA, António de Oliveira. História geral das guerras angolanas, 2v. Lisboa: Agencia Geral das Colónias. 1972.

\section{CARSTENS, Peter.}

In the Company of Diamonds: De Beers, Kleinzee, and the control of a town. Athens: Ohio University Press. 2001.

CARVALHO, Vasques de.

Relatório anual de saúde. Arquivo da Diamang. Direcção Administrativa. Serviços de Saúde. Pasta 126B,9-4; relatórios médicos, de 1 ago. 1933 a 30 set. 1937 (Museu de Antropologia da Universidade de Coimbra, Coimbra). 1936.

CARVALHO, Vasques de.

Relatório mensal de saúde. Arquivo da Diamang. Direcção Administrativa. Serviços de Saúde. Pasta 126B,9-2 $2^{\circ}$; relatórios médicos, de 1 ago.
1927 a 31 jul. 1930 (Museu de Antropologia da Universidade de Coimbra, Coimbra). jan. 1930.

CARVALHO, Vasques de.

Relatório anual de saúde. Arquivo da Diamang. Serviços de Saúde. Pasta 126B,9-1º; relatórios médicos, de 21 nov. 1921 a 31 jul. 1927 (Museu de Antropologia da Universidade de Coimbra, Coimbra). 1926.

CASTELO, Cláudia.

O modo português de estar no mundo: o lusotropicalismo e a ideologia colonial portuguesa, 1933-1961. Porto: Afrontamento. 1998.

CdAA.

Companhia do Açúcar de Angola. Companhia do Açúcar de Angola, 4 de março 1920- 4 de março 1940. Lisboa: Bertrand. 1941.

CdC.

Companhia de Cabinda. Relatório de contas do Conselho de Administração e parecer do Conselho Fiscal. Lisboa: s.n. 1957.

\section{CEAUP.}

Centro de Estudos Africanos da Universidade do Porto (Coord.). Trabalho forçado africano: o caminho de ida. Porto: Ceaup/Universidade do Porto. 2009.

\section{CLARENCE-SMITH, Gervaise.}

The third Portuguese empire 1825-1975.

Manchester: Manchester University Press. 1985.

CLEVELAND, Todd.

Minors in name only: child laborers on the diamond mines of the Companhia de Diamantes de Angola (Diamang), 1917-1975. Journal of Family History, v.35, n.1, p.91-110. 2010.

CLEVELAND, Todd.

Rock solid: African laborers on the diamond mines of the Companhia de Diamantes de Angola (Diamang), 1917-1975, Dissertação (Doutorado em Filosofia) - University of Minnesota, Minneapolis. 2008.

CLEVELAND, Todd.

The life of a Portuguese colonialist: general José Norton de Matos (1867-1955). Dissertação (Mestrado) - University of New Hampshire, Durham. 2000.

COSTA, Mário.

Carta para Ernesto de Vilhena. Arquivo da Diamang. Secção da Mão-de-Obra Indígena. Pasta $86 \mathrm{~B}, 1^{\circ}$; inspecções médicas a contratados, de 25 ago. 1934 a 24 ago. 1967 (Museu de Antropologia da Universidade de Coimbra, Coimbra). 14 jul. 1950. 
CURTIN, Philip D.

The end of the "white man's grave"? Nineteenthcentury mortality in West Africa. Journal of Interdisciplinary History, v.21, n.1, p.63-88. 1990.

DAVID, José Henriques Santos.

[Entrevista]. Entrevistador: Jorge Varanda. Entrevista gravada em minidisc. Depoimento concedido à investigação de doutoramento, no Estoril. Arquivo pessoal do autor. 27 jan. 2004.

DAVID, José Henriques Santos.

Memória para a reunião médica regional de Luanda. Dundo: Companhia de Diamantes de Angola/ Direcção dos Serviços de Saúde. 1957.

DAVID, José Henriques Santos.

Alguns aspectos da assistência médico-sanitária no Concelho do Chitato (Lunda, Angola). Lisboa: Companhia de Diamantes de Angola. 1965.

DERRICK, Jonathan.

The "native clerk" in colonial West Africa.

African Affairs, v.82, n.326, p.61-74. 1983.

DIAMANG.

Companhia de Diamantes de Angola. Relatório do Conselho de Administração, Lisboa: Diamang. 1946.

\section{DIAMANG.}

Companhia de Diamantes de Angola. Estatutos: contrato entre o governo-geral da Província de Angola e a Diamang. Lisboa: Diamang. 1921.

DIAS, Jill.

Famine and disease in the history of Angola, c. 1830-1930. Journal of African History, v.22, n.3, p.349-378. 1981.

DIAS, José Pedro Sousa.

Índice de drogas medicinais angolanas em documentos dos séculos XVI a XVIII. Revista Portuguesa de Farmácia, v.45, n.4, p.174-184. 1995.

DIONNE, Jessica.

Malaria workers in Southern Mozambique: state employees in the transition from late colonialism to independence. Dissertação (Doutorado) The School of Oriental and African Studies, University of London, London. 2011.

ECKERT, Andreas.

An African rural entrepreuneurs and labour in Cameroon. The Journal of African History, v.40, n.1, p.109-126. 1999.

EGGERMONT, P.; SHALER, M.K.

Carta para a Direç̧ão Técnica de Bruxelas.

Arquivo da Diamang. Secção do Pessoal. Pasta Dr. Vasques Carvalho (Museu de Antropologia da Universidade de Coimbra, Coimbra). 12 jun. 1927.
ESTEVES, Emmanuel.

O Caminho de Ferro de Benguela e o impacto econômico, social e cultural na sua zona de influência 1902-1952. Dissertação (Doutorado em Letras) - Faculdade de Letras, Universidade do Porto, Porto. 1999.

FARLEY, John.

Bilharzia: a history of imperial tropical medicine. Cambridge: Cambridge University Press. 1991.

FONSECA, Elísio Dias da.

Breves apontamentos acerca de alguns problemas médicos e da ocupação sanitária do Ultramar. Anais do Instituto de Medicina Tropical, Lisboa, v.10, n.4, fasc.1, (número dedicado ao Primeiro Congresso Nacional de Medicina Tropical). p.2369-2372. 1953.

FREUDENTHAL, Aida Faria.

Angola. In: Serrão, Joel; Oliveira Marques, António Henriques de (Dir.). Nova história da expansão portuguesa, v.11: O império africano, 1890-1930. Lisboa: Estampa. p.259-467. 2001.

GALVÃO, Henrique.

Exposição do deputado Henrique Galvão à Comissão de Colónias da Assembleia Nacional, em janeiro de 1947. Arquivo Histórico-

Parlamentar; Henrique Galvão; caixa 48, n.10 (Assembleia da República, Lisboa). jan. 1947.

HAILEY, William Malcolm, lord. An African survey: a study of problems arising in Africa South of the Sahara. London: Oxford University Press. 1938.

HEYWOOD, Linda M.

The growth and decline of African agriculture in central Angola, 1890-1950. Journal of Southern African Studies, v.13, n.3, p.355-371. 1987.

\section{HEWA, Soma.}

Colonialism, tropical disease, and imperial medicine: Rockefeller philanthropy in Sri Lanka. New York: Cambridge University Press. 1996.

HUNT, Nancy R.

A colonial lexicon of birth ritual, medicalization and mobility in the Congo. Durham: Duke University Press. 1999.

ILO.

International Labour Organization. Report of the Committee of Experts on the Application of Conventions and Recommendations: International Labour Conference, $56^{\text {th }}$ session, report 3, part 4 . Geneva: ILO. 1971.

ILO.

International Labour Organization. Official Bulletin, n.45, supl. 2, n.2. 1962. 
ILO.

International Labour Organization. Report of the ad hoc committee on forced labor. Memorandum of February 22, 1952. Geneva: ILO. 1953.

JARA, António Bellini.

[Entrevista]. Entrevistador: Jorge Varanda. Entrevista manuscrita. Depoimento concedido à investigação de doutoramento, em Coimbra. Arquivo pessoal do autor. 2 mar. 2004.

KANANOJA, Kalle.

Central African identities and religiosity in colonial Minas Gerais. Dissertação (Doutorado) - Åbo Akademi University, Ảbo. 2012.

KANANOJA, Kalle.

Healers, idolaters, and good christians: a case study of creolization and popular religion in mid-eighteenth century Angola. International Journal of African Historical Studies, v.43, n.3, p.443-465. 2010.

KUMWENDA, Linda Beer.

African medical personnel of the Universities' Mission to Central Africa in Northern Rhodesia. In: Hardiman, David (Ed.). Healing bodies, saving souls: medical missions in Asia and Africa. New York: Rodopi. p.193-226. 2006.

LAWRANCE, Benjamin N.; OSBORN, Emily Lynn; ROBERTS, Richard L.

Intermediaries, interpreters, and clerks: African employees in the making of colonial Africa. Madison: University of Wisconsin Press. 2006.

LYONS, Maryiens.

The colonial disease: a social history of sleeping sickness in Northern Zaire, 1900-1940.

Cambridge: Cambridge University Press. 1991.

MANDERSON, Lenore.

Sickness and the state: health and illness in colonial Malaya, 1870-1940. New York: Cambridge University Press. 1996.

MATOS, Victor Manuel d'Albuquerque. [Entrevista]. Entrevistador: Jorge Varanda. Entrevista manuscrita. Depoimento concedido à investigação de doutoramento, em Coimbra. Arquivo pessoal do autor. 15 dez. 2004.

MORA, Damas.

Les organisations sanitaires en general: organisation sanitaire de l'Angola. Congresso Colonial Nacional, 2., 1924, Lisboa. Teses e Actas das Sessões. Lisboa: Sociedade de Geografia de Lisboa. p.171-183. 1924.

NEWITT, Malyn.

Portugal in Africa: the last hundred years. London: Hurst. 1981.
NEWPORT, Glenn H.

Carta para Administração. Arquivo da Diamang. Pasta 84K,3-4 Diamang, Lunda; Ocupação e Diversos, de 1 ago. 1923 a 30 nov. 1923 (Museu de Antropologia da Universidade de Coimbra, Coimbra). 16 nov. 1923.

PACKARD, Randall.

White plague, black labour: tuberculosis and the political economy of health and disease in South Africa. Berkeley: University of California Press. 1989.

PATTERSON, David K.

Health in colonial Ghana: disease, medicine and socio-economic change, 1900-1955. Waltham: Crossroads. 1981.

PÉLISSIER, René.

História das campanhas de Angola: resistência e revoltas, 1845-1941. 2v. Lisboa: Estampa. 1986-1988.

PERRINGS, Charles.

Good lawyers but poor workers: recruited Angolan labour in the copper mines of Katanga, 1917-1921. The Journal of African History, v.18, n.2, p.237-259. 1977.

PICOTO, José.

Relatório anual de saúde. Arquivo da Diamang. Direcção Administrativa. Serviços de Saúde. Pasta 126B,9- $10^{\circ}$; relatórios mensais e anuais, de jul. 1955 a out. 1956 (Museu de Antropologia da Universidade de Coimbra, Coimbra). 1955.

PICOTO, José.

Relatório anual de saúde. Arquivo da Diamang. Direç̧ão Administrativa. Serviços de Saúde. Pasta folder $126 \mathrm{~B}, 9-8^{\circ}$; relatórios médicos, de jan. 1950 a jun. 1952 (Museu de Antropologia da Universidade de Coimbra, Coimbra). 1950.

PICOTO, José.

Relatório anual de saúde. Arquivo da Diamang. Direç̧ão Administrativa. Serviços de Saúde.

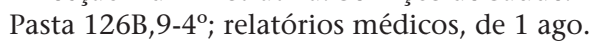
1933 a 30 set. 1937 (Museu de Antropologia da Universidade de Coimbra, Coimbra). 1935.

PINA, Luiz de.

Historia da medicina imperial portuguesa (Angola). Boletim Geral das Colónias, separata n.211. 1943.

PRAKASH, Gyan.

Subaltern studies as postcolonial criticism. American Historical Review, v.99, n.5, p.1475-1490. 1994.

PORTO, Nuno.

Modos de objectificação da dominação colonial: o caso do Museu do Dundo, 1940-1970. Lisboa: Fundação Calouste Gulbenkian; Fundação para a Ciência e a Tecnologia. 2009. 
REDINHA, José.

Etnias e culturas de Angola. Luanda: Instituto de Investigação Científica de Angola. 1975.

RELATÓRIO...

Relatório dos peritos da Organização Mundial de Saúde que em 1962 se deslocaram às províncias da Guiné, Angola e Moçambique a convite do governo português. Boletim Geral do Ultramar, v.39, n.456-457, p.115-122. 1963.

ROSS, Edward Alsworth.

Report on the employment of native labor in Portuguese Africa. New York: The Abbott Press. 1925.

SANTOS, Francisco Ferreira dos.

Reorganização dos serviços de saúde coloniais com o objectivo de se dar um maior desenvolvimento aos serviços de assistência médica aos indígenas. Conferência Económica do Império Colonial Português, 1., 1936, Lisboa. Lisboa: Tipografia de Cristóväo Augusto Rodrigues. (Separata). 1936.

SHALER, Millard K.; VAN BRÉE, F. Carta de Bruxelas para Lisboa, com relatório do doutor Gillet. Arquivo da Diamang. Serviços de Saúde. Pasta 126B,9-1; ; relatórios médicos, de 21 nov. 1921 a 31 jul. 1927 (Museu de Antropologia da Universidade de Coimbra, Coimbra). 4 jan. 1922.

SHAPIRO, Martin F.

Medicine in the service of colonialism: medical care in Portuguese Africa, 1885-1974. Dissertação (Doutorado) - Universidade da Califórnia, Los Angeles. 1983.

STOLER, Anna Laura.

Along the archival grain: epistemic, anxieties and colonial common sense. New Jersey: Princeton University Press. 2009.

TELO, António José.

Economia e império no Portugal contemporâneo. Lisboa: Cosmos. 1994.

TUCKER, John T.

Drums in darkness. New York: Doran. 1927.

VAN ONSELEN, Charles.

African mine labor in southern Rhodesia, 1900-1933. Johannesburg: Ravan. 1976.

VAN ONSELEN, Charles.

Black workers in central African industry: a critical essay on the historiography and sociology of Rhodesia. Journal of Southern African Studies, v.1, n.2, p.228-246. 1975.
VARANDA, Jorge.

Filhos, enteados e apadrinhados: discursos, políticas e práticas dos serviços de saúde da Diamang. Antropologia Portuguesa, v.29, p.141-165. 2012.

VARANDA, Jorge.

A asa protectora de outros: as relações transcoloniais do Serviço de Saúde da Diamang. In: Bastos, Cristiana; Barreto, Renilda (Ed.). Circulação do conhecimento médico. Lisboa: Imprensa de Ciências Sociais. p.339-372. 2011.

VARANDA, Jorge.

Crossing colonies and empires: the health services of the Diamond Company of Angola. In: Digby, Anne; Ernst, Waltraud; Muhkarji, Projit B. (Ed.). Crossing colonial historiographies. Cambridge: Cambridge Scholars Publishing. p.165-184. 2010.

VARANDA, Jorge.

"A bem da nação": medical science in a diamond company in twentieth-century colonial Angola. Dissertação (Doutorado) - University College London, London. 2007.

WALKER, Timothy.

Doctors, folk medicine and the Inquisition: the repression of magical healing in Portugal during the Enlightenment. Leiden: Brill. 2005.

WALKER, Timothy.

Sorceres and folkhealers: Africans and the Inquisition in Portugal, 1680-1800. Revista Lusófona de Ciência das Religiões, v.3, n.5-6, p.83-98. 2004a.

WALKER, Timothy.

The role and practices of the curandeiro and saludador in early modern Portuguese society. História, Ciências, Saúde - Manguinhos, Rio de Janeiro, v.11, sup.1, p.223-237. 2004b.

WALTER, Jaime.

Subsídios para a história dos serviços de saúde do ultramar, $1^{\text {a }}$ parte: Província de Angola. Arquivos de Angola, separata, p.35-36. 1953.

WEBER, Max. Economy and society: an outline of interpretative sociology. Roth, Guenther; Wittich, Claus (Ed.). Berkeley: University of California Press. 1978. 